\title{
Spectral analysis of pipe-to-soil potentials with variations of the Earth's magnetic field in the Australian region
}

\author{
R. A. Marshall, ${ }^{1}$ C. L. Waters, ${ }^{2}$ and M. D. Sciffer ${ }^{2}$
}

Received 22 November 2009; revised 13 January 2010; accepted 16 January 2010; published 20 May 2010.

[1] Long, steel pipelines used to transport essential resources such as gas and oil are potentially vulnerable to space weather. In order to inhibit corrosion, the pipelines are usually coated in an insulating material and maintained at a negative electric potential with respect to Earth using cathodic protection units. During periods of enhanced geomagnetic activity, potential differences between the pipeline and surrounding soil (referred to as pipe-to-soil potentials (PSPs)) may exhibit large voltage swings which place the pipeline outside the recommended "safe range" and at an increased risk of corrosion. The PSP variations result from the "geoelectric" field at the Earth's surface and associated geomagnetic field variations. Previous research investigating the relationship between the surface geoelectric field and geomagnetic source fields has focused on the high-latitude regions where line currents in the ionosphere $E$ region are often the assumed source of the geomagnetic field variations. For the Australian region $S q$ currents also contribute to the geomagnetic field variations and provide the major contribution during geomagnetic quiet times. This paper presents the results of a spectral analysis of PSP measurements from four pipeline networks from the Australian region with geomagnetic field variations from nearby magnetometers. The pipeline networks extend from Queensland in the north of Australia to Tasmania in the south and provide PSP variations during both active and quiet geomagnetic conditions. The spectral analyses show both consistent phase and amplitude relationships across all pipelines, even for large separations between magnetometer and PSP sites and for small-amplitude signals. Comparison between the observational relationships and model predictions suggests a method for deriving a geoelectric field proxy suitable for indicating PSP-related space weather conditions.

Citation: Marshall, R. A., C. L. Waters, and M. D. Sciffer (2010), Spectral analysis of pipe-to-soil potentials with variations of the Earth's magnetic field in the Australian region, Space Weather, 8, S05002,

doi:10.1029/2009SW000553.

\section{Introduction}

[2] Australia contains many thousands of kilometers of pipeline that conveys natural resources to population centers. For example, gas pipelines are constructed of materials that allow high pressures but are susceptible to corrosion. The pipelines are routinely monitored for integrity to ensure the reliable supply of resources. Since corrosion is a chemical process, one of the main corrosion mitigation techniques is to record the pipe-to-soil potential (PSP) and maintain a sufficient voltage to inhibit the

\footnotetext{
${ }^{1}$ IPS Radio and Space Services, Bureau of Meteorology, Sydney, New South Wales, Australia.

${ }^{2}$ Centre for Space Physics, School of Mathematical and Physical Sciences, University of Newcastle, Callaghan, New South Wales, Australia.
}

transfer of pipe material to the soil. This process is complicated by the PSPs induced by natural variations of the geomagnetic field and associated ionospheric currents [Gummow and Eng, 2002].

[3] Previous research in this area has identified Geomagnetic Induced Currents (GICs) as the major source of variations in the PSPs routinely recorded on long pipelines [Campbell, 1978, 1986; Boteler and Seager, 1998]. GICs have their ultimate source in the dynamics of space weather. The interaction between the solar wind and the Earth's magnetic field, in addition to neutral atmosphere tide effects from solar heating, generates electric currents in the near-Earth space environment (magnetosphere and ionosphere). These currents and their associated geomagnetic and geoelectric field perturbations induce currents in the Earth which are the GICs primarily responsible for the 


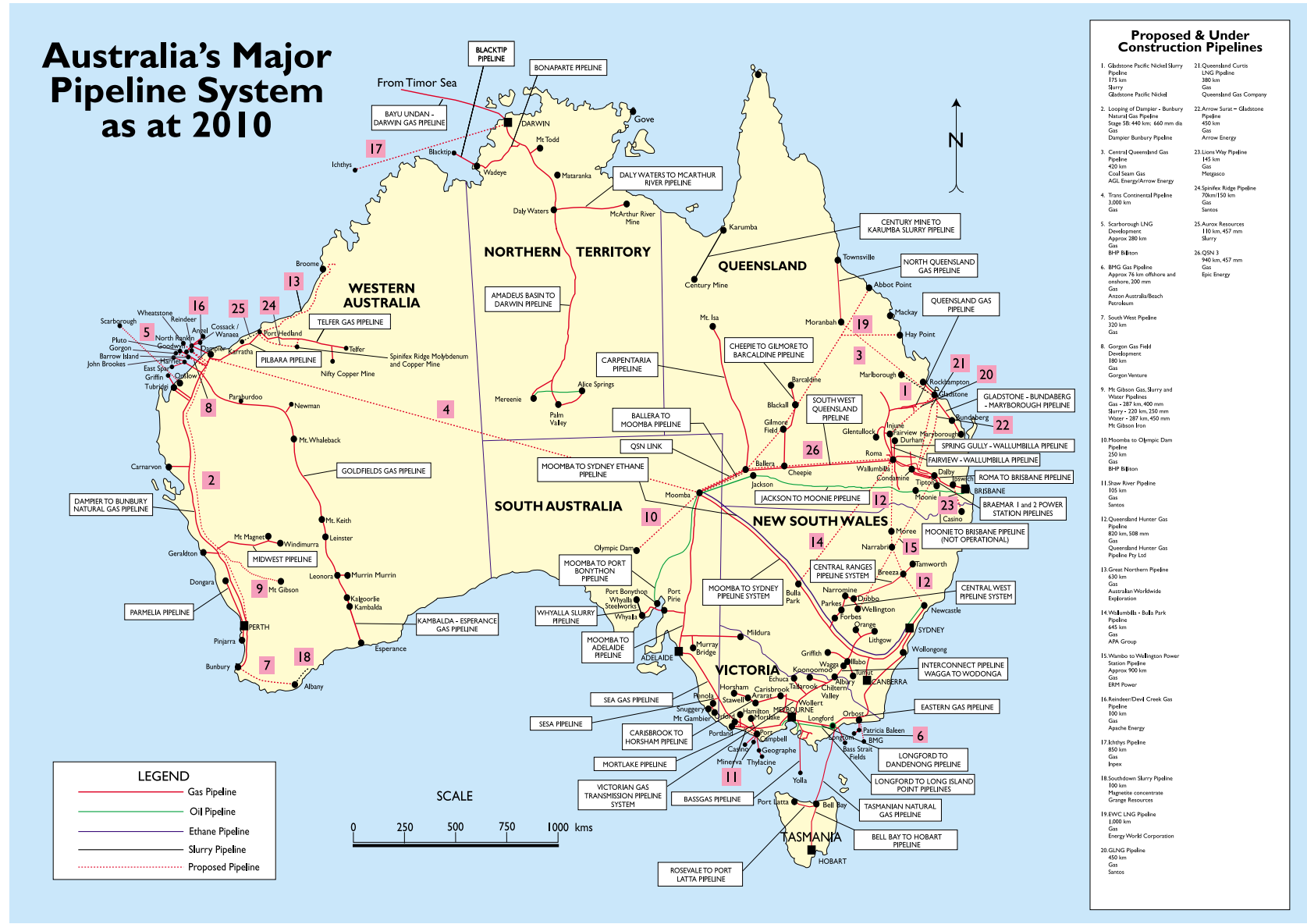

Figure 1. Map of pipeline networks for the Australian region. The pipeline segments used for this study are the North QLD Gas Pipeline which runs from Yabula to Moranbah, the QLD Gas Pipeline which runs from Rockhampton to Wallumbilla in southern QLD, the Eastern Gas Pipeline which runs from Sydney (NSW) to Longford in Victoria, and the TAS Natural Gas Pipeline which runs from Longford to Hobart. Magnetometers located near Townsville $\left(19.27^{\circ} \mathrm{S}, 146.82^{\circ} \mathrm{E}\right)$, Canberra $\left(35.28^{\circ} \mathrm{S}, 149.22^{\circ} \mathrm{E}\right)$, and Hobart $\left(42.88^{\circ} \mathrm{S}, 147.35^{\circ} \mathrm{E}\right)$ were used for analysis with QLD, NSW, and TAS pipeline data, respectively. Map compiled and published by Great Southern Press. All copyright remains with Great Southern Press (www.pipeliner.com.au).

large variations in PSPs observed by many pipeline operators [Pirjola, 1982, 2002; Pulkkinen et al., 2001b]. The potential difference influences the electrochemical environment at the surface of the pipe, leading to corrosion [Gummow and Eng, 2002]. The performance of cathodic protection systems (CPS) that are used to bias the potential in an effort to combat this electrochemical process may be degraded by GICs and the associated naturally occurring geomagnetic field variations.

[4] GICs have previously been studied at high latitudes where the effects of geomagnetic disturbances can be large. At high latitudes the Birkeland current system produces large deviations in the geomagnetic field, particularly during disturbed periods. In Finland and Canada, a number of studies have examined GICs and their effects on power transmission lines and oil pipelines [Campbell,
1978, 1986; Viljanen and Pirjola, 1994a, 1994b; Pulkkinen et al., 2001a; Trichtchenko and Boteler, 2002; Pirjola, 2005; Pulkkinen et al., 2008]. Similar studies have also been conducted in the Tierra del Fuego region of South America [Osella et al., 1998; Osella and Favetto, 2000]. Large GICs have been correlated with the largest rate of change of the geomagnetic field [Viljanen, 1997; Viljanen et al., 1999; Trichtchenko and Boteler, 2004] and simulations of PSPs on Canadian and Scandinavian pipelines have also been conducted [Boteler and Seager, 1998; Pulkkinen et al., 2001b; Trichtchenko and Boteler, 2002; Fernberg et al., 2007]. GIC signals observed on low-latitude pipelines [Martin, 1993; Waters et al., 2006] are likely to have different ionospheric source fields to those observed on high-latitude pipelines and provide additional spectral information for comparison with model predictions. 
(a)

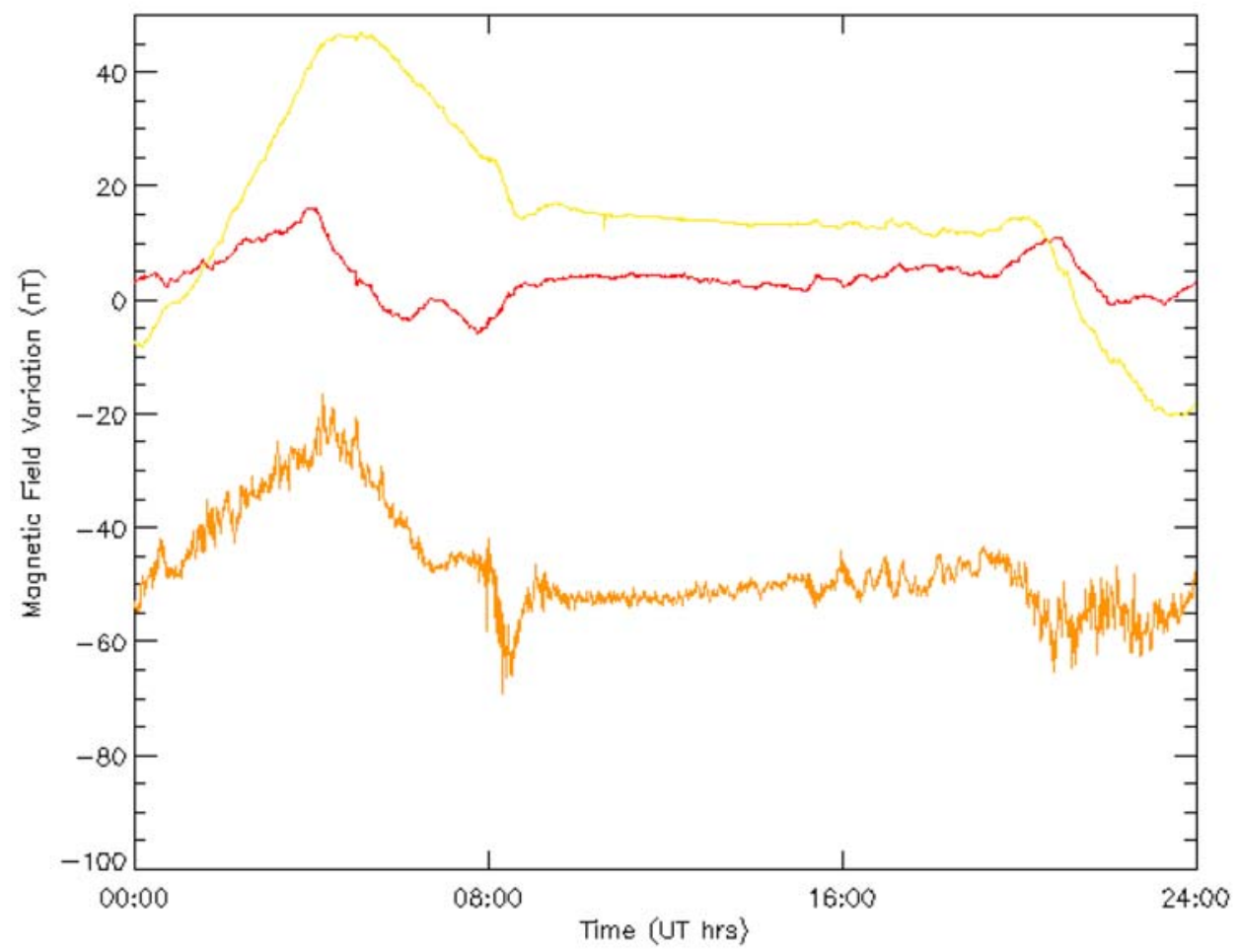

(b)

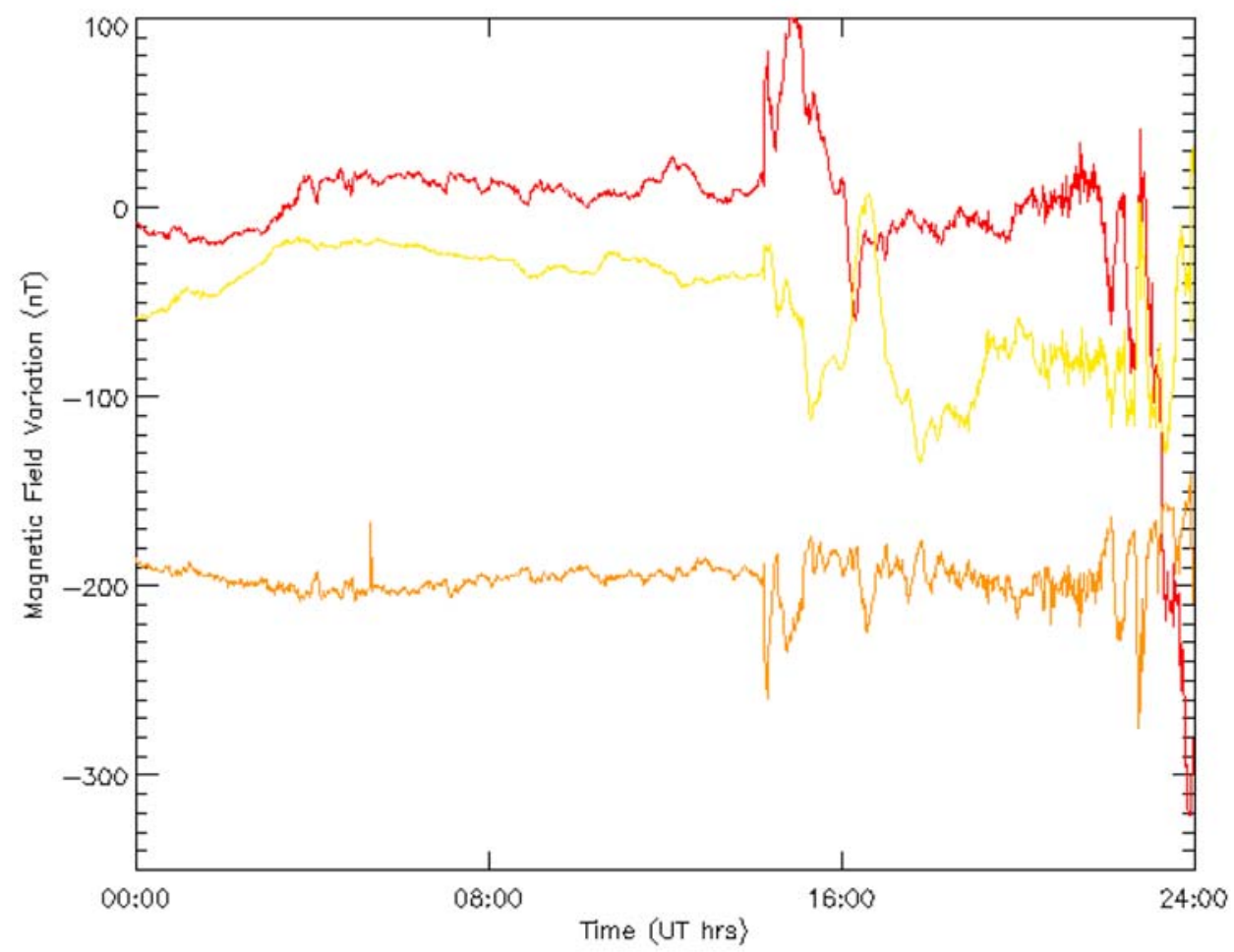

Figure 2 
[5] There are a variety of phenomena which contribute to the spectrum of geomagnetic variations observed on the ground at Australian latitudes. The solar quiet $(S q)$ current system is observed during local daytime and is primarily caused by solar heating of the atmosphere as the Earth rotates [Campbell, 1989]. The $S q$ current system focus is usually located at latitudes around \pm 30 degrees and is observed during geomagnetic quiet conditions over much of central northern Australia [Stening et al., 2005]. Pipelines under the $S q$ current system will be influenced by the time variation and the associated GIC as reported by Waters et al. [2006]. This current system is not observed in highlatitude studies. The occurrence rate and intensity of magnetospheric substorms are linked with solar activity with a typical substorm lasting a few hours. The amplitude and frequency content of geomagnetic variations that occur during substorms changes with latitude. The spectrum of ULF geomagnetic variations greater than $5 \mathrm{nT}$ extends to at least $60 \mathrm{mHz}$ for data recorded in Tasmania [Waters et al., 1991, 1994]. There are also geomagnetic perturbations with tens of minute period that vary in amplitude and frequency content with latitude, time of day and solar activity.

[6] Australia has a somewhat unique advantage when studying the effects of GICs in pipelines. The continent spans a large latitudinal and longitudinal range with the associated variety of magnetospheric and ionospheric current systems. Australia has a large network of long and short pipelines over wide conductivity contrasts (e.g., coastal effects and other conducting anomalies) and magnetometer data from a large array are available for studying the mechanisms responsible for GICs in pipelines. This paper investigates how the range in time and amplitude scales for geomagnetic variations observed over the Australian region relates to the spectrum of PSPs observed on pipelines.

\section{Pipeline and Data Networks}

[7] Australia has an extensive pipeline network of thousands of kilometers that carries oil, gas and other resources vital for everyday life (Figure 1). This study presents the results of a spectral analysis of PSPs observed on four pipeline segments from the Australian region: the North Queensland (QLD) Gas Pipeline; the QLD Gas Pipeline; the Eastern Gas Pipeline which runs from New South Wales (NSW) to Victoria, and the Tasmanian (TAS) Natural Gas Pipeline. The PSPs measured at various points along these pipeline segments were analyzed with respect to variations measured in the Earth's magnetic field by magnetometers located near Townsville $\left(19.27^{\circ} \mathrm{S}\right.$, $\left.146.82^{\circ} \mathrm{E}\right), \mathrm{Canberra}\left(35.28^{\circ} \mathrm{S}, 149.22^{\circ} \mathrm{E}\right)$ and Hobart $\left(42.88^{\circ} \mathrm{S}\right.$, $147.35^{\circ} \mathrm{E}$ ) for analysis with QLD, NSW, and TAS pipeline data, respectively. The data from the north QLD pipeline were recorded during October-November 2004 while the data from the remaining pipelines (southern QLD, NSW and TAS) were recorded 14-18 December 2006. In most cases, the magnetometer sites were at least one hundred kilometers from the locations at which the PSPs were measured.

[8] Figure 2a shows time series of PSPs on a pipeline in north Queensland and magnetic field variations measured at a nearby location on a geomagnetic "quiet day." The solar heating associated $S q$ current effects on the upper atmosphere are the dominant feature of this geomagnetic time series. Figure $2 b$ shows time series of PSPs measured on a Tasmanian pipeline with magnetic field variations recorded at a nearby location on a disturbed day when effects of a geomagnetic storm dominate the magnetometer data. Both the PSP and magnetometer data were sampled at 1 min intervals. Figures $2 a$ and $2 b$ show considerable similarity between variations in the magnetometer signals and the PSP data.

\section{Data Analysis}

[9] The analysis focused on obtaining spectral information on the relationship between the PSPs and variations in the horizontal components of the geomagnetic field. Both the PSP and magnetometer data were sampled at 1 min intervals which results in a Nyquist frequency of $8.3 \mathrm{mHz}$ and hence the spectral information presented in this paper is for a bandwidth of $0-8.3 \mathrm{mHz}$.

[10] The data were first viewed as a time series and checked for "discontinuities" and "steps" as these anomalies in the time domain contaminate the spectral representation. This significantly reduced the data available for spectral analysis as typically $50 \%$ of the PSP data were recorded at cathodic protection units (CPUs) where the feedback system resulted in most positive voltage swings being limited to zero volts for a duration that gave a "square hat function" appearance to the time series. The most significant loss of data due to the square hat function in the time series was for PSP data from the NSW pipeline.

[11] Prior to transforming the data into the frequency domain using the fast Fourier transform, a Hanning window was applied to the selected time series. The cross power, cross phase and "effective impedance" spectra were then calculated. The effective impedance is defined here as the ratio of the PSP spectral amplitude to geomagnetic field spectral amplitude for each frequency in the spectra. The PSP is the result of the geoelectric field integrated over the distance between grounding points so the ratio of the geoelectric field to the geomagnetic field

Figure 2. Time series over a $24 \mathrm{~h}$ interval of $\mathrm{H}$ - and $\mathrm{D}$-component magnetometer data (red and yellow, respectively) and pipeline PSP data (orange) measured on a nearby pipeline recorded during (a) geomagnetic quiet day on 5 October 2004 in north QLD and (b) a geomagnetic active day on 14 December 2006 in TAS. The PSP data are measured in volts and scaled by a factor of 100 with an offset applied for presentation. Local time is UT plus $10 \mathrm{~h}$. 
(a)

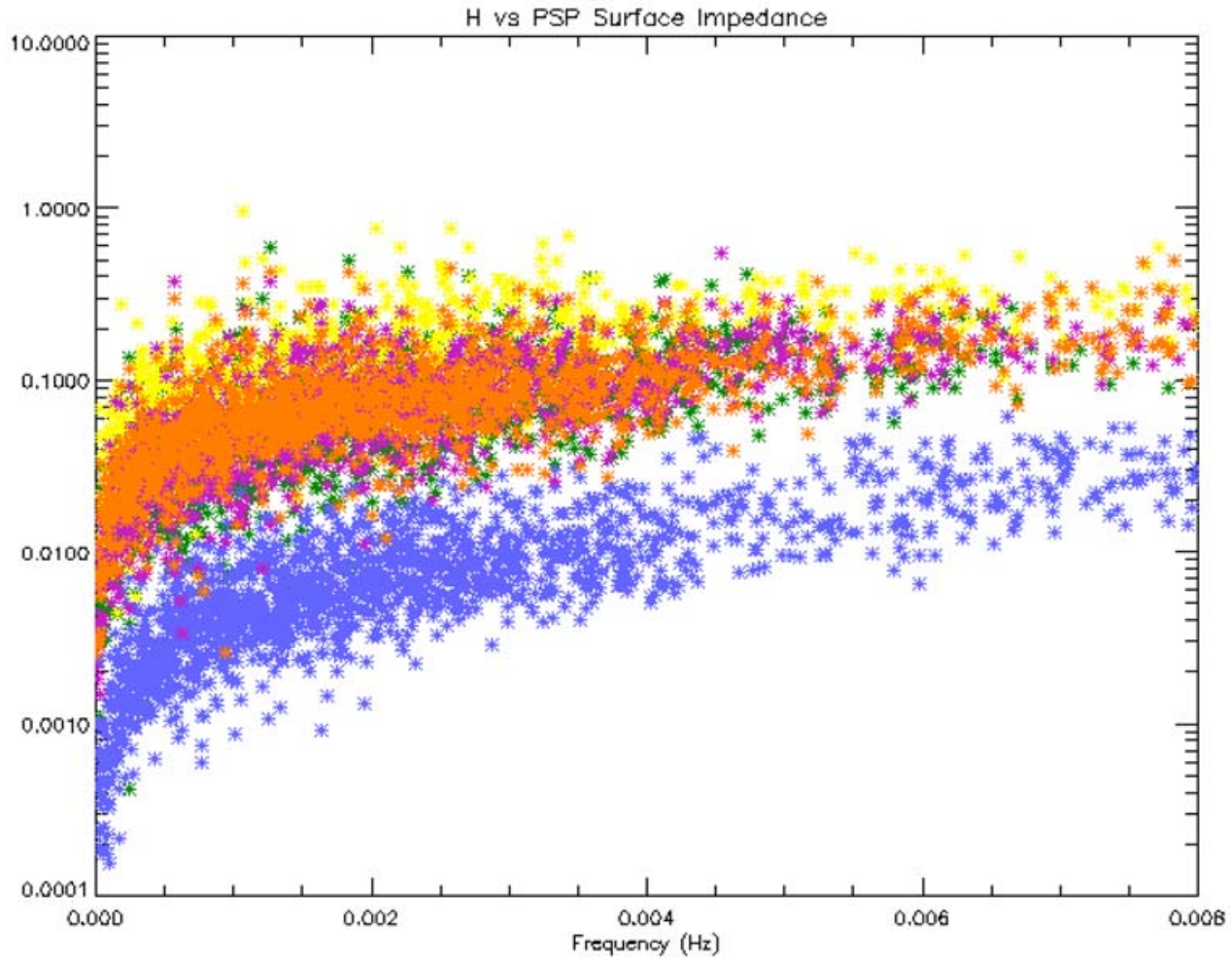

(b)

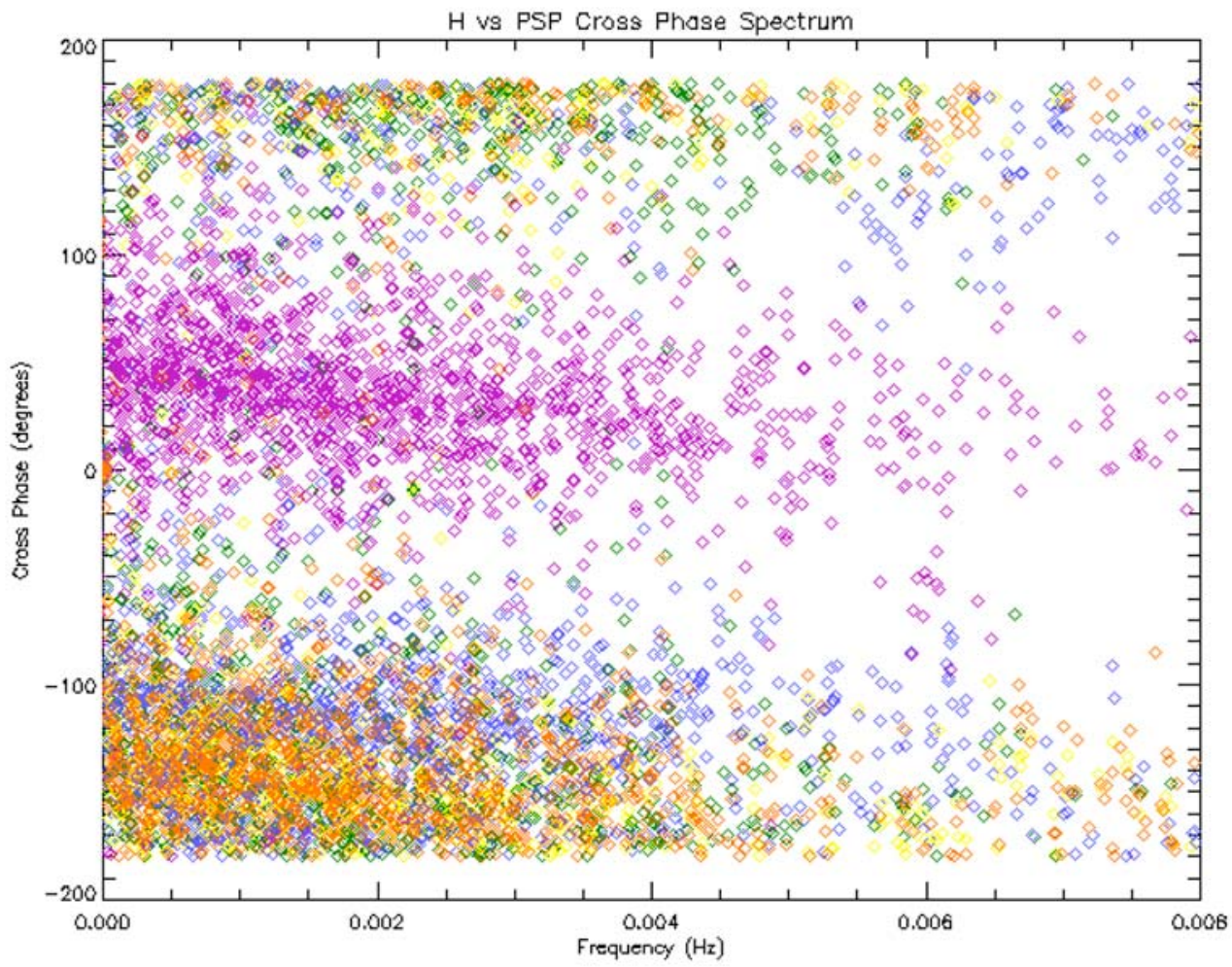

Figure 3 
can be thought of as the effective impedance. The cross phase gives the phase difference between the signals for each frequency component of the spectra and cross power gives a measure of power common to both signals. The spectral information was calculated using data from each useable day and effective impedance amplitude and crossphase values for frequencies where the associated cross power was below a selected threshold were discarded. Values where the associated cross power was greater than the threshold were then combined to produce scatterplots of effective impedance amplitude and cross-phase values as a function of frequency. All suitable PSP sites from a given pipeline were then combined onto respective scatterplots for each data analysis period, e.g., 14-18 December, for each of the four pipeline segments analyzed.

\section{Results}

[12] Figure 3 shows the combined spectral analysis results for five PSP sites on the northern QLD pipeline and Charters Towers magnetometer $\mathrm{H}$-component data for selected intervals during October-November 2004. The southern most PSP site at Moranbah is several hundred kilometers from the magnetometer. The effective impedance spectra show curves of similar shape with a scale factor of 1-2 orders of magnitude between Moranbah and the other sites. The cross-phase spectra show approximately linear trends for all sites over the bandwidth. In addition, the phase values for one of the PSP sites located on a lateral pipeline section are approximately $180^{\circ}$ out of phase with the other PSP sites. This result will be discussed later. Similar spectral results were obtained using the magnetometer D-component data.

[13] Figure 4a shows the results for the spectral analysis of the southern QLD pipeline PSP data with the Charters Towers magnetometer $\mathrm{H}$-component data from the period 14-18 December 2006. The pipeline is several hundred kilometers from the magnetometer location with some sections greater than $1000 \mathrm{~km}$. The effective impedance curves show similar trends to those obtained for the northern QLD pipeline. The cross-phase spectra show linear trends similar to those of Figure 3 , with a $180^{\circ}$ phase difference between some PSP sites.

[14] Figure 4b shows the spectral analysis results of the NSW pipeline PSP data with the Canberra magnetometer $\mathrm{H}$-component data for 14-18 December 2006. The useable data available for this analysis was very limited due to most PSP data being recorded at locations where feedback contaminated the spectra. The effective impedance curves show similar trends to those obtained in Figure 3. The cross-phase spectra show linear trends similar to those of Figure 3, although the slope of the linear phase trend is of opposite sign.

[15] Figure 4c shows the spectral analysis of the TAS pipeline PSP data with the Hobart magnetometer $\mathrm{H}$ component data from the period 14-18 December 2006. The effective impedance and cross-phase curves show similar trends to those obtained in Figure 3, although the magnitude of the slope of the linear phase trend is larger. A $180^{\circ}$ phase difference is observed between some PSP sites.

\section{Discussion and Modeling}

[16] The spectral analysis presented in section 3 shows a great deal of consistency across the pipeline data. The effective impedance curves are reasonably consistent between different pipelines across the Australian region and between PSP sites from the same pipeline. The linear cross-phase structure extends over the $0-8.3 \mathrm{mHz}$ band and is also reasonably consistent between different pipelines across the Australian region and between PSP sites from the same pipeline. The consistent trends observed between the pipeline PSPs and the geomagnetic field variations, sometimes recorded hundreds of kilometers apart, imply a strong coupling between geomagnetic field variations and the pipeline PSPs.

[17] The trends in the effective impedance curves are consistent with the E/B ratio given by Campbell [1986] and Pirjola [1982] and the $180^{\circ}$ phase difference is consistent with PSP signals on either side of a pipeline insulating joint [Boteler and Seager, 1998]. The order of magnitude difference between the effective impedance curves for different PSP sites on a pipeline may be due to the distance between grounding points, or pipeline orientation with respect to the source fields.

[18] The general consistency between amplitude and phase spectra observed for different pipelines across the Australian region, and within a particular pipeline segment, implies reasonable agreement should be observed with theoretical models. Modeling of GICs due to variations of the geomagnetic field and their impacts on man-made infrastructures such as pipelines and power networks is generally treated as a two-step process [Pirjola, 2002]. The first step is to determine the geoelectric field and the next step involves applying the calculated geoelectric field to the engineering problem for the appropriate infrastructure. The geoelectric field has been applied to the calculation of GICs in power networks using Kirchhoff's current laws [Viljanen and Pirjola, 1994a] and Complex Image methods

Figure 3. Spectra of effective impedance (a) PSP/H-component amplitude ratio and (b) PSP/H-component cross phase for Woodstock PSP (green), Moranbah PSP (blue), Yabula PSP (yellow), Woodstock lateral PSP (pink), and Stuart Lateral PSP (orange) data analyzed with Charters Towers magnetometer H-component data. The plots show the combined results from the spectral analyses of all suitable days within the period October-November 2004. 
(a)

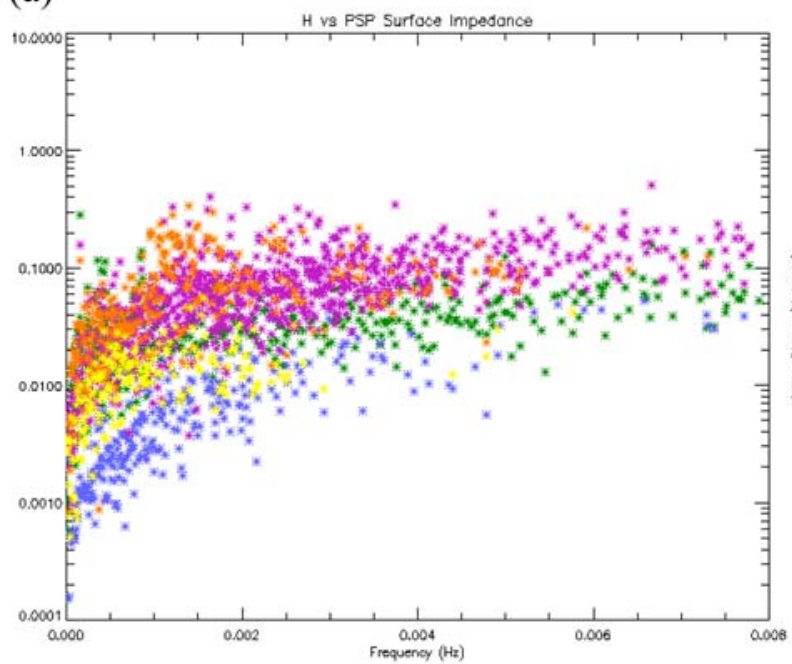

(b)

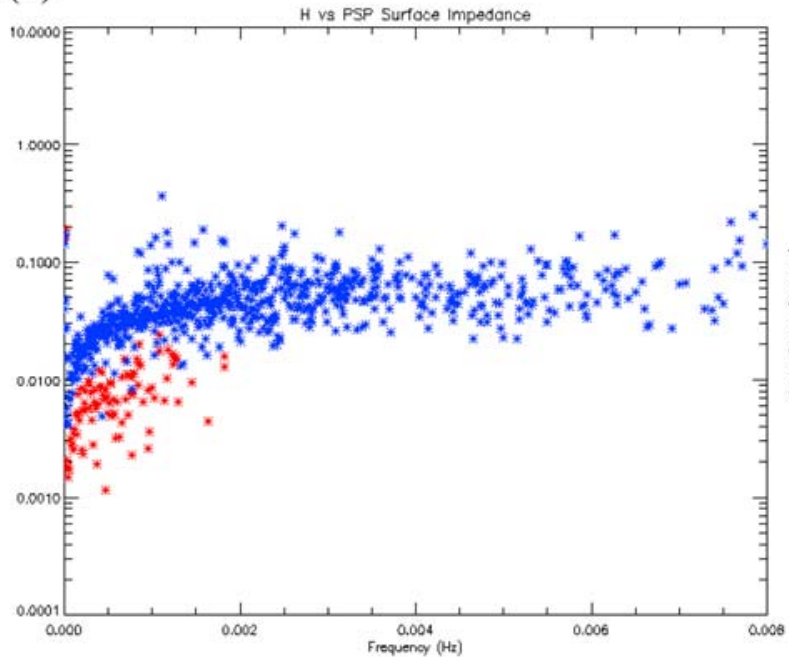

(c)

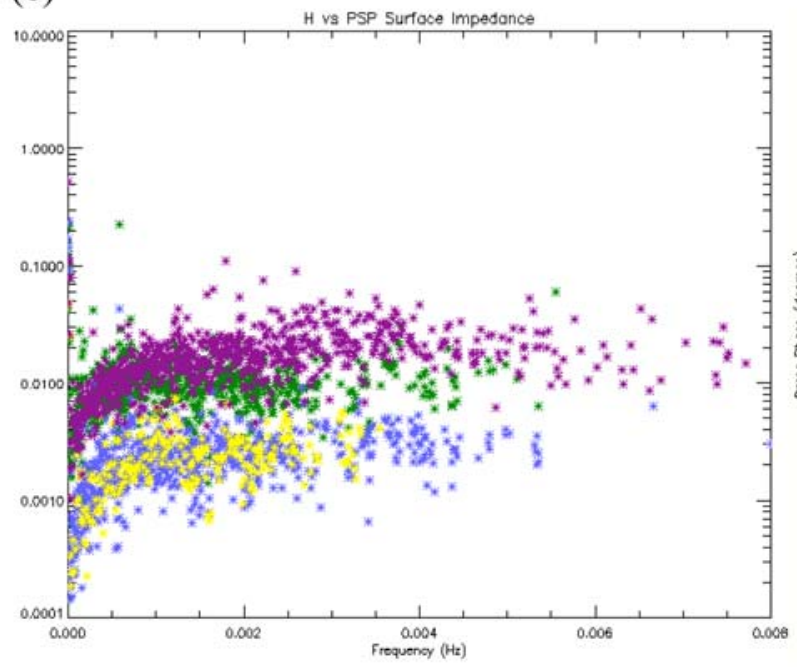

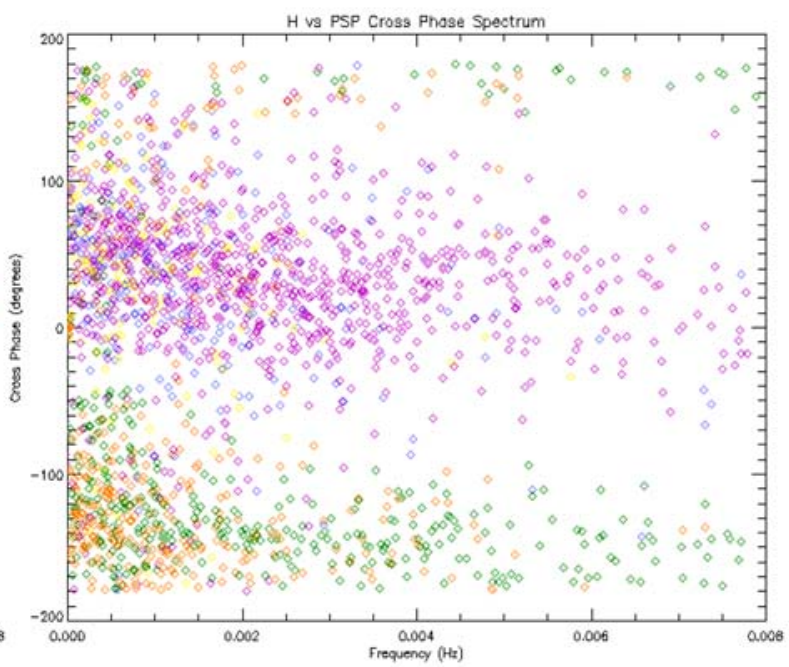
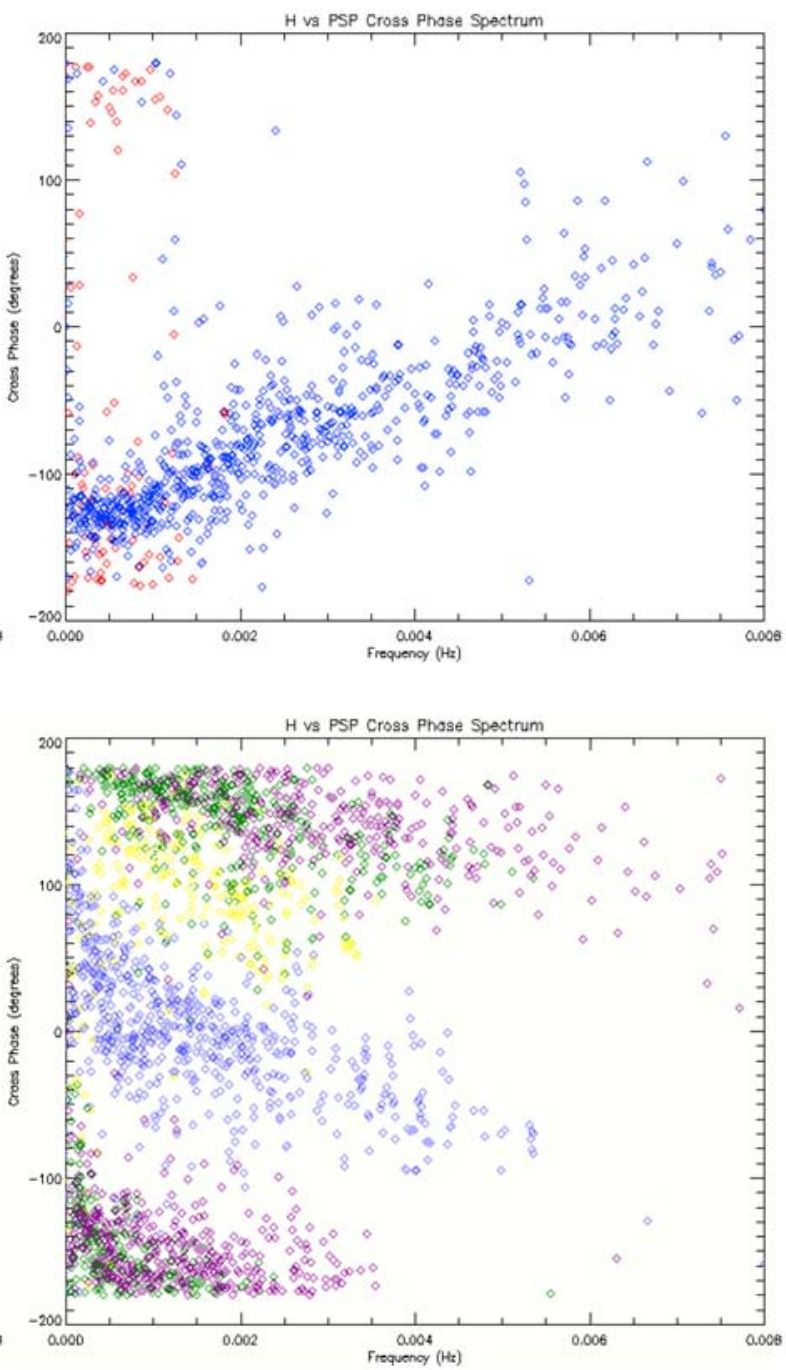

Figure 4 
[Viljanen et al., 1999], and to the calculation of PSPs using Distributed Source Transmission Line (DSTL) theory [Boteler and Seager, 1998; Boteler, 2000; Pulkkinen et al., 2001b; Trichtchenko and Boteler, 2002].

[19] Determination of the geoelectric field from the geomagnetic field data have been performed in both the time domain [Pirjola, 2002; Hejda and Bochnicek, 2005] and the frequency domain [Pirjola, 1982, 2002; Trichtchenko and Boteler, 2002]. In the frequency domain, the simplest model assumes the Earth is a uniformly conducting half-space and the magnetic source field can be represented by a vertically downward propagating plane wave. This approach gives the equation of magnetotellurics [e.g., Cagniard, 1953; Pirjola, 1982] which relates the orthogonal electric and magnetic field components at the Earth's surface by

$$
E_{y}=-\sqrt{\frac{\omega}{\mu_{0} \sigma}} B_{x} e^{i \frac{\pi}{4}}
$$

For an N-layer Earth conductivity model, the orthogonal geoelectric and geomagnetic field components are related using a frequency-dependent surface impedance [Trichtchenko and Boteler, 2002] given by

$$
Z_{n}=i \omega \mu\left(\frac{1-r_{n} \exp \left(-2 k_{n} d_{n}\right)}{k_{n}\left(1+r_{n} \exp \left(-2 k_{n} d_{n}\right)\right.}\right)
$$

Anisotropic conductivity models employ a tensor to describe the Earth's conductivity both vertically and horizontally [Lilley et al., 2001; Caldwell et al., 2004]. The influence of conductivity anisotropy on the effects of geomagnetic activity, such as those due to coastal effects, have been studied by Viljanen and Pirjola [1994b], Osella and Favetto [2000], Beamish et al. [2002], Osella et al. [2002], Olsen and Kuvshinov [2004], and Fernberg et al. [2007]. Further complications arise when the ionospheric current systems giving rise to the magnetic source fields have significant horizontal structure. Line currents and finite width current sheets have been used to simulate ionospheric electrojet currents [Pirjola, 1982; Viljanen and Pirjola, 1994a, 1994b; Favetto and Osella, 1999; Pirjola, 2002] and U-shaped geometries [Pirjola and Viljanen, 1998; Viljanen et al., 1999] have been used to simulate field-aligned current systems typically observed at high latitudes. These geometries result in reasonably complicated formula for geoelectric field determination from geomagnetic field measurements and are not considered further here. In this paper, the observed spectra (Figures 3 and 4) are compared with the $\mathrm{E} / \mathrm{H}$ amplitude ratio and phase relationships as a function of frequency determined by equations (1) and (2).

[20] Figure 5 shows scatterplots of amplitude and phase spectra typical of those observed in Figures 3 and 4 with the predicted amplitude and phase relationships from equations (1) and (2) given by the blue and green lines, respectively. The $\mathrm{N}$-layer Earth conductivity model given by Trichtchenko and Boteler [2002] was used to determine the green line of Figure 5 and has been reproduced in Table 1. The red line was determined using an $\mathrm{N}$-layer Earth conductivity model appropriate to the Australian region taken from the results of an induction study by Campbell et al. [1998] as given in Table 1. A scalar conductivity value of $\sigma=0.02 \mathrm{~S} / \mathrm{m}$ was used to determine the values described by the blue line. The observations show reasonable agreement with all three lines predicted by equations (1) and (2).

[21] The close agreement suggests that a reasonable proxy for the geoelectric field may be obtained from geomagnetic field data processed through a simple frequency domain filter with normalized amplitude and phase characteristics represented by

$$
Z(f)=\sqrt{\frac{f}{f_{N}}} e^{i \frac{\pi}{4}}
$$

where $f_{N}$ is the Nyquist frequency. Figures 6 and 7 show the results of processing geomagnetic field data in this manner for geomagnetic "active" and "quiet" days, respectively. Figure 6 shows data for 7 November 2004 when the 3 hourly ap index reached 207 and Figure 7 is for 13 November 2004 when the maximum 3 hourly ap index was 9 . Figures $6 a$ and $7 a$ show the magnetometer $H-$ and D-component variations recorded at Charters Towers in northern QLD in red and yellow, respectively, with Figures $6 b$ and $7 b$ showing the time derivative of the magnetometer data $(\mathrm{dB} / \mathrm{dt})$ in green, the magnetometer data processed with the filter of equation (3) in blue (referred to here as GE data), and the PSP data from the nearby pipeline in orange. The correlation coefficient for the PSP and $\mathrm{dB} / \mathrm{dt}$ data of Figure 6 is 0.40 , while the correlation coefficient for the PSP and GE data is 0.80 . For Figure 7, the analogous correlation coefficients are 0.55 for PSP and $\mathrm{dB} / \mathrm{dt}$ data and 0.93 for PSP and GE data. A similar result was observed when applying equation (3) to magnetometer data recorded at locations nearby the pipeline segments in southern QLD, NSW, and TAS. Correlation coefficients were typically $0.3-0.4$ higher for GE data than $\mathrm{dB} / \mathrm{dt}$ data when analyzed with respect to the PSP data observed on nearby pipelines. These results

Figure 4. Effective impedance amplitude and cross-phase spectra in similar format to Figure 3 for PSP data measured on pipeline segments from (a) Queensland Gas Pipeline, southern QLD; (b) Eastern Gas Pipeline, NSW; and (c) Tasmanian Natural Gas Pipeline analyzed using H-component magnetometer data recorded near Townsville, Canberra, and Hobart, respectively. 
(a)

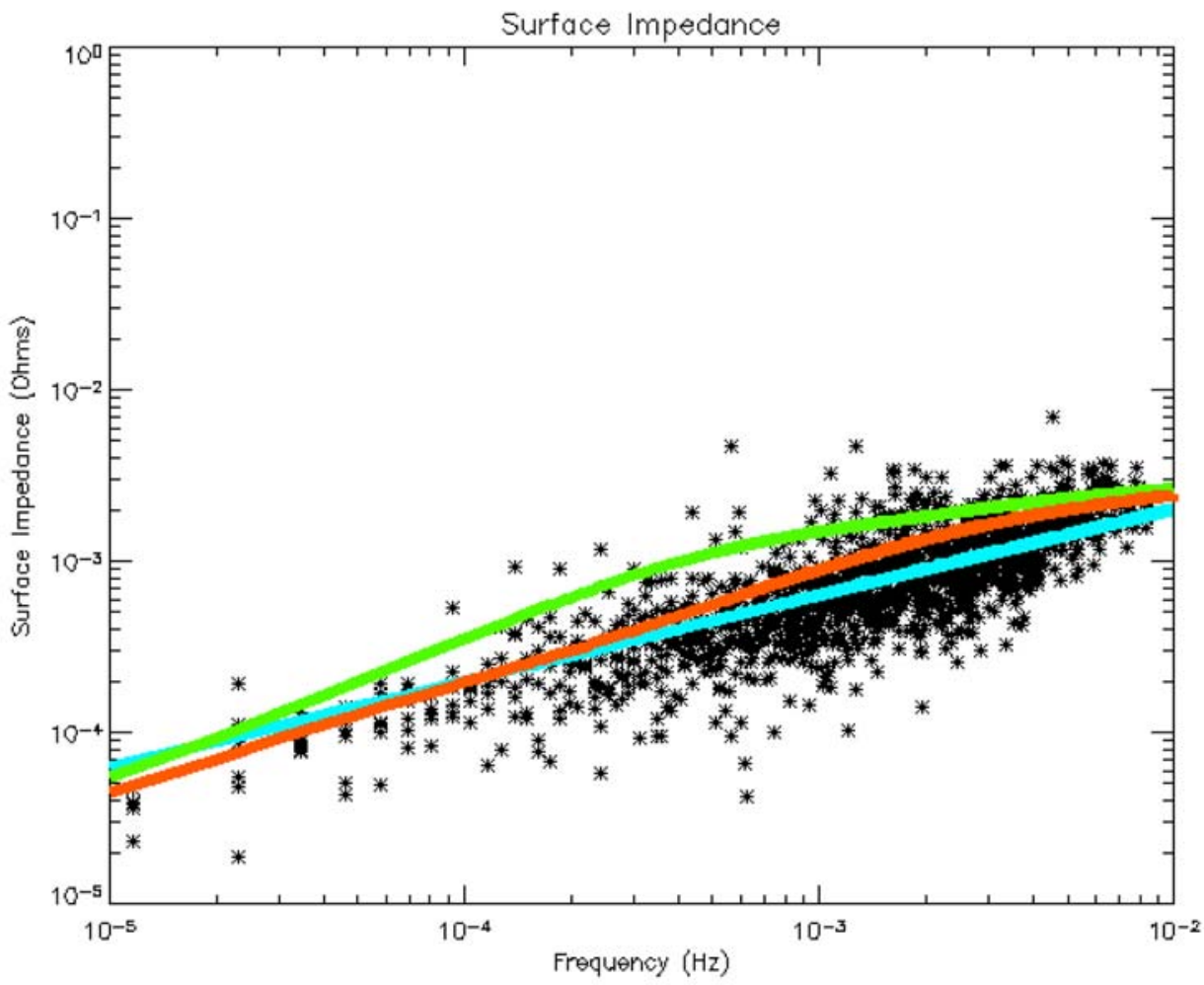

(b)

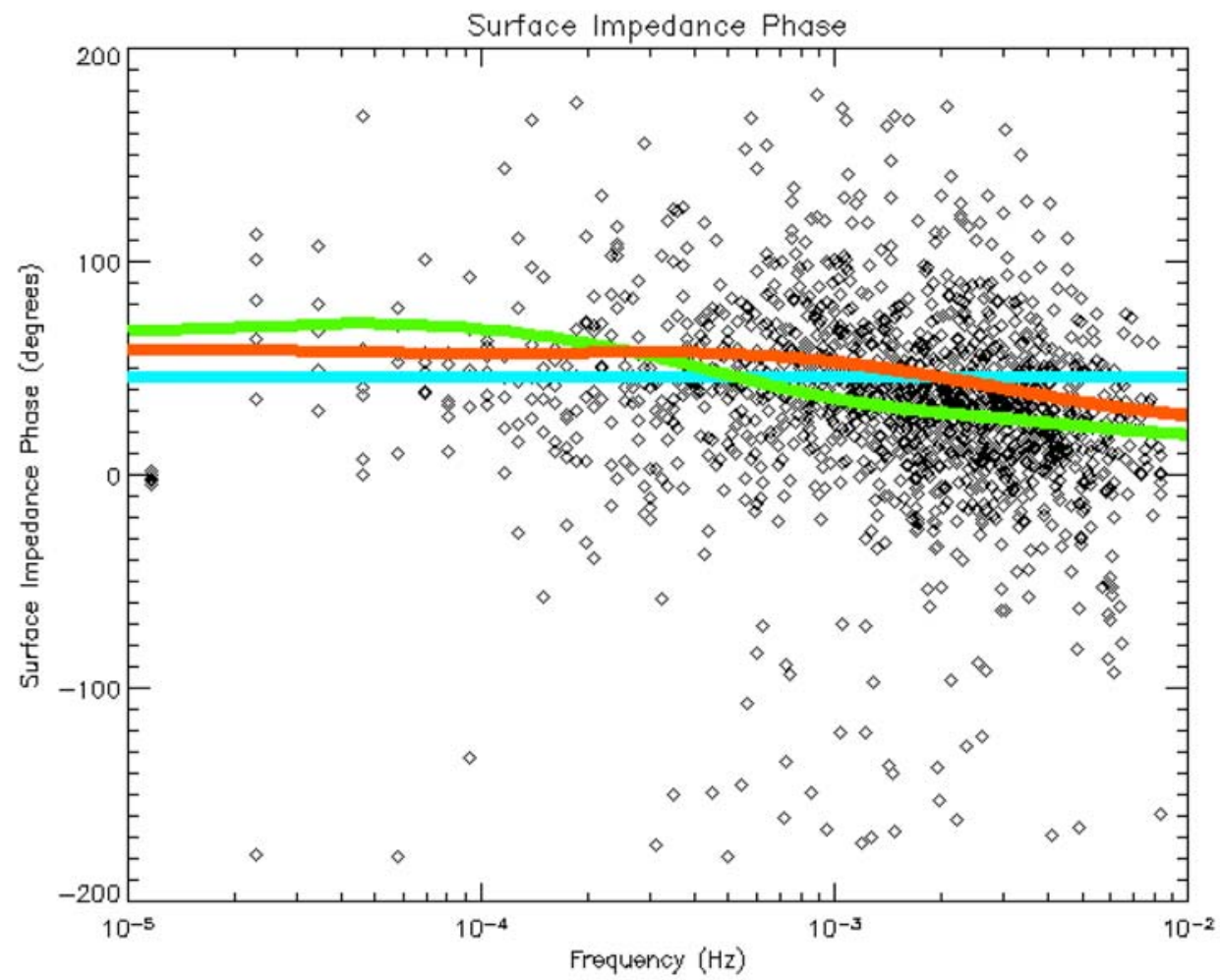

Figure 5 
Table 1. N-Layer Earth Model Resistivity Values ${ }^{\mathrm{a}}$

\begin{tabular}{cccc}
\hline Layer Number & Layer Thickness $(\mathrm{km})$ & Trichtchenko and Boteler [2002] Resistivity $(\Omega \mathrm{m})$ & Campbell et al. [1998] Resistivity $(\Omega \mathrm{m})$ \\
\hline 1 & 0.025 & 50 & 50 \\
2 & 6 & 20 & 20 \\
3 & 15 & 5000 & 1000 \\
4 & 25 & 300 & 250 \\
5 & 60 & 3000 & 25 \\
6 & 300 & 300 & 25 \\
\end{tabular}

${ }^{a}$ Values used to evaluate the equation (2) predictions represented by the green and red lines of Figure 5 . The resistivity values given by Trichtchenko and Boteler [2002] are appropriate for the northwest region of Canada and were used to determine the green line of Figure 5. The resistivity values for Australia were manually scaled from a conductivity study of the corresponding region by Campbell et al. [1998] and were used to determine the red line of Figure 5.

are consistent with some of the findings published by Trichtchenko and Boteler [2004].

\section{Space Weather Implications}

[22] Due to the variability of space weather conditions and the associated GICs, maintaining the appropriate bias voltage on the cathodic protection systems of longpipeline infrastructure is an ongoing challenge for corrosion engineers. The Australian Standard AS2832 [Australian members of Joint Standards Australia/Standards New Zealand Committee MT-014, 2004, p. 14] (section 2.2.2.6, Telluric current effects, part b) specifies how the effectiveness of the CPUs should be monitored. It states, "The potential of structures that are subject to telluric current effects shall not be more positive than the protection criteria for more than $10 \%$ of the test period. When determining the extent of the potential variation, an assessment should be made of the degree of ionospheric disturbances at the time of the interval." The provider of information on the degree of ionospheric disturbance is identified in Appendix A (section A4, Telluric Effects) as "the Australian IPS Radio and Space Services" (www.ips.gov.au). Presently, IPS Radio and Space Services provide $\mathrm{K}$ and $\mathrm{A}$ index information derived from locally recorded geomagnetic field data as a measure of ionospheric activity. The results from this study suggest a more suitable index, (e.g., GIC index), could be derived from geomagnetic field data processed using equation (3).

[23] Typically, GIC studies employ $\mathrm{dB} / \mathrm{dt}$ data as an indicator of space weather conditions and its impact on pipelines and power networks [Viljanen, 1997; Viljanen et al., 1999; Boteler et al., 1998; Kappenman, 2001; Trichtchenko and Boteler, 2004]. This study shows that a GIC index could be used to provide a better indicator of GIC-related space weather conditions compared with $\mathrm{A}$ index, $\mathrm{K}$ index or $\mathrm{dB} / \mathrm{dt}$ data. The improvement of such a GIC index over $\mathrm{dB} / \mathrm{dt}$ is due to the frequency dependence between the geoelectric field and $\mathrm{dB} / \mathrm{dt}$ as discussed by Pirjola [1982].
The applicability of $\mathrm{dB} / \mathrm{dt}$ over $\mathrm{A}$ and $\mathrm{K}$ indices as an indicator of GIC activity is discussed by Trichtchenko and Boteler [2004]. Further, the GIC index defined in this paper can be derived entirely from geomagnetic field data and does not require knowledge of the Earth's conductivity, ionospheric current geometry and the relevant infrastructure details required for the more accurate simulations of PSPs [Boteler and Seager, 1998; Osella et al., 1998; Favetto and Osella, 1999; Pulkkinen et al., 2001b; Trichtchenko and Boteler, 2002; Fernberg et al., 2007]. The GIC index would be an indicator of space weather activity applicable to both pipeline and power networks. It is envisaged that the GIC index would be derived from both horizontal geomagnetic field components and users would select the index aligned with their particular infrastructure system. The cadence of such an index would be every minute and average thresholds applicable to specific infrastructures could be determined from statistical studies such as those by Viljanen and Pirjola [1989] applied to the time integral of geomagnetic field data.

\section{Conclusions}

[24] This study presents the results of a spectral analysis of PSP measurements recorded at various locations on four pipeline segments across the Australian region with geomagnetic field data recorded by nearby magnetometers. The analysis showed both consistent phase and amplitude relationships across all pipelines, even for large separations between magnetometer and PSP sites and for small-amplitude signals. Comparison between the observational relationships and model predictions suggests a method for deriving a geoelectric field proxy directly from magnetometer data, defined here to be the GIC index. This index is considered more suitable than indices such as the $\mathrm{A}$ and $\mathrm{K}$ indices and $\mathrm{dB} / \mathrm{dt}$ data typically used to indicate GIC-related space weather conditions.

Figure 5. Effective impedance (a) amplitude ratio and (b) cross-phase plots showing a comparison of observations from one PSP site of Figure 3 (symbols) and model predictions of equations (1) (blue line) and (2) (green and red lines indicate model predictions using the conductivity models given in Table 1). A log-frequency scale has been used to emphasize the power law relationship in the amplitude spectrum. 
(a)

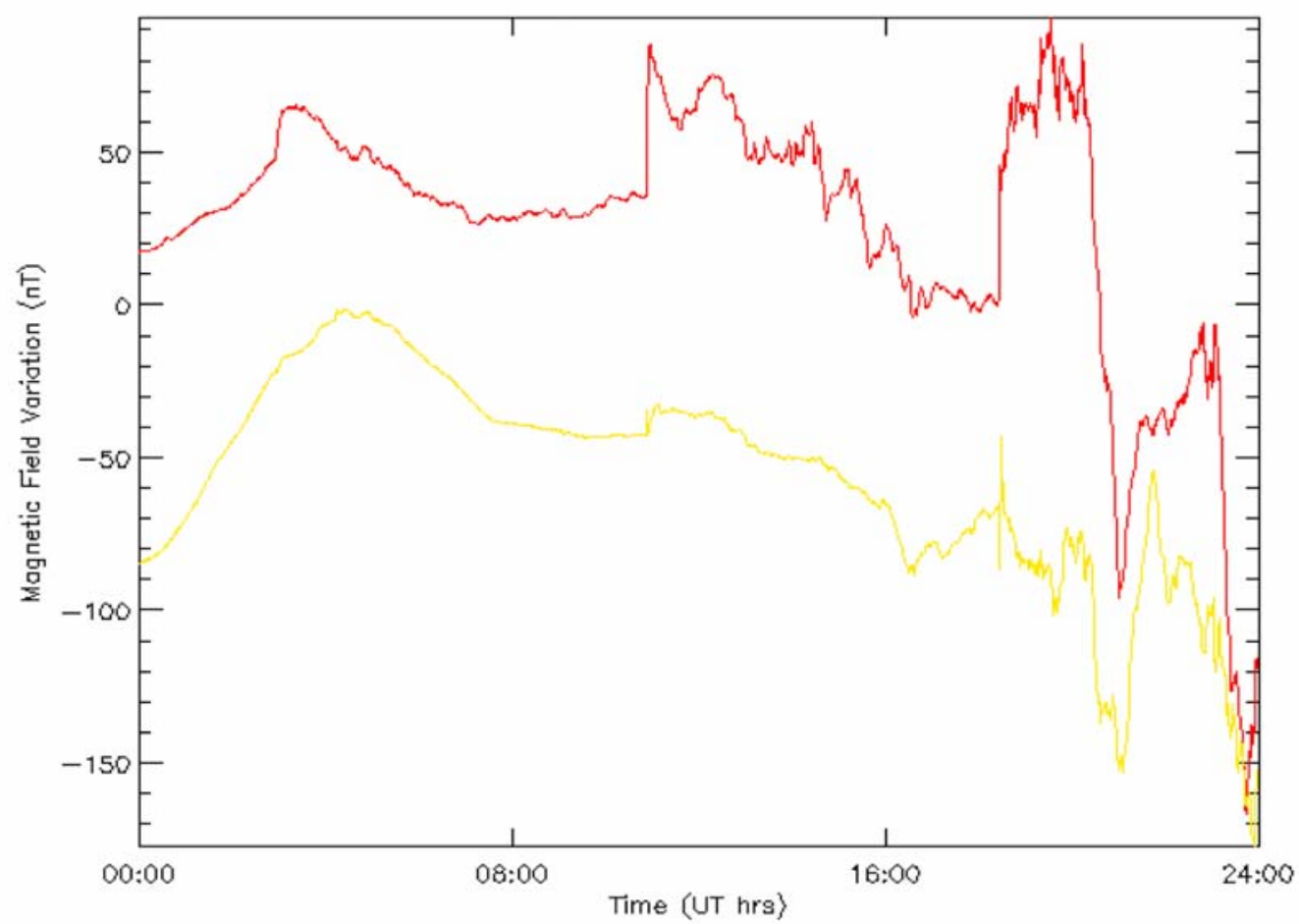

(b)

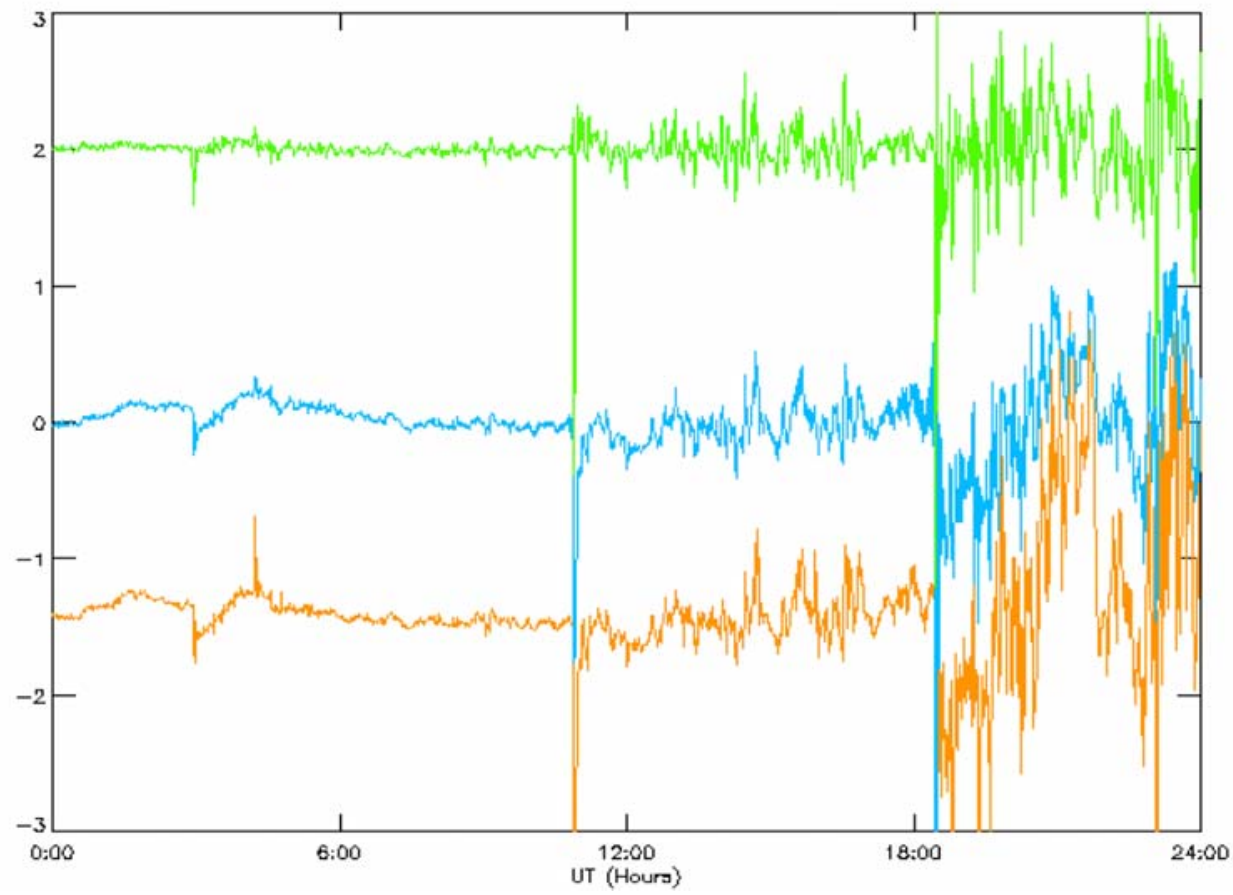

Figure 6. Plots of (a) Charters Towers magnetometer H- and D-component data (red and yellow, respectively) and (b) $\mathrm{dB} / \mathrm{dt}$ data (green) scaled by factor 0.1 with offset applied for presentation, GE data (blue) scaled by factor 0.1, and PSP data (orange) in volts recorded in north QLD during a geomagnetic active day, 7 November 2004. 
(a)

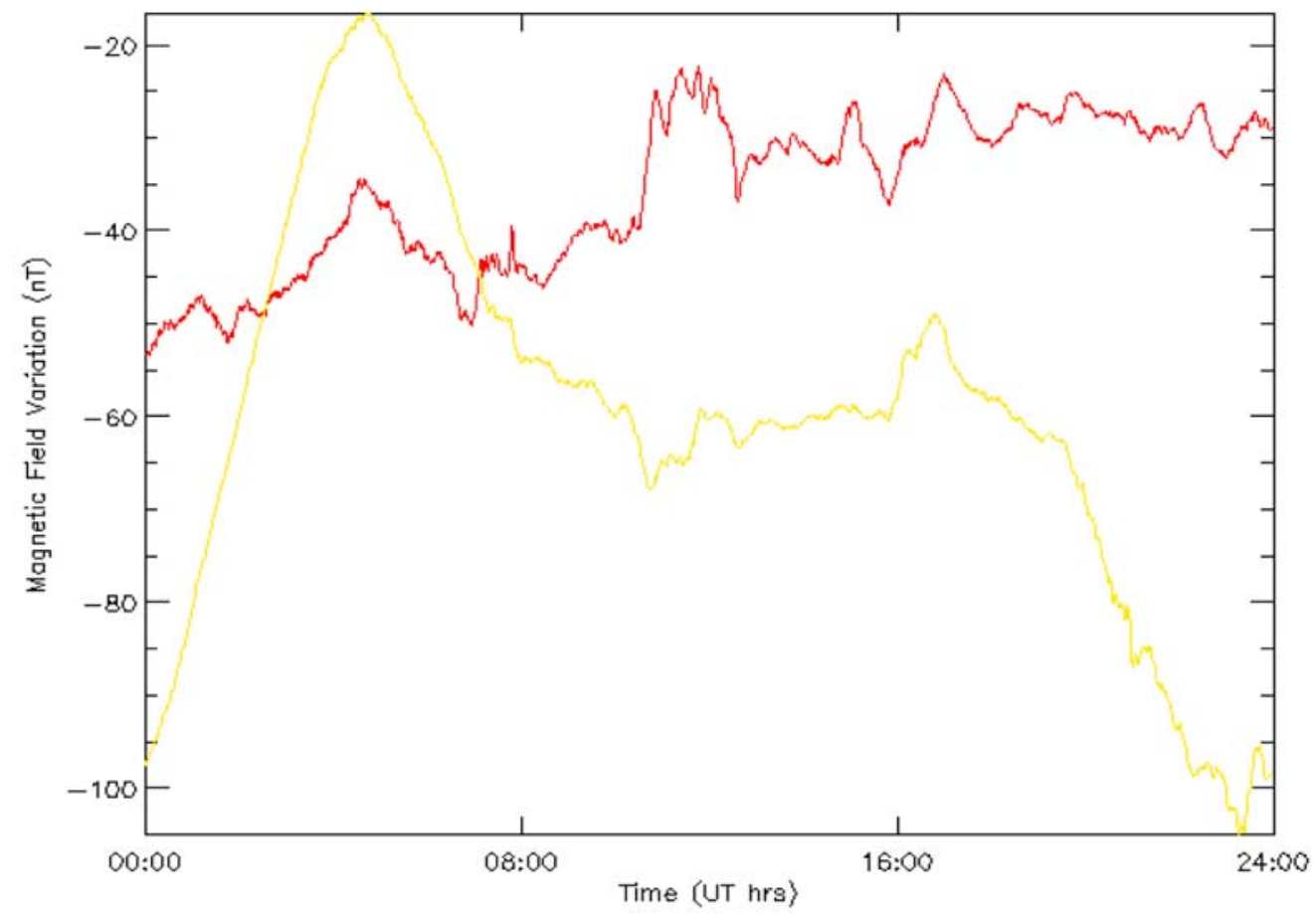

(b)

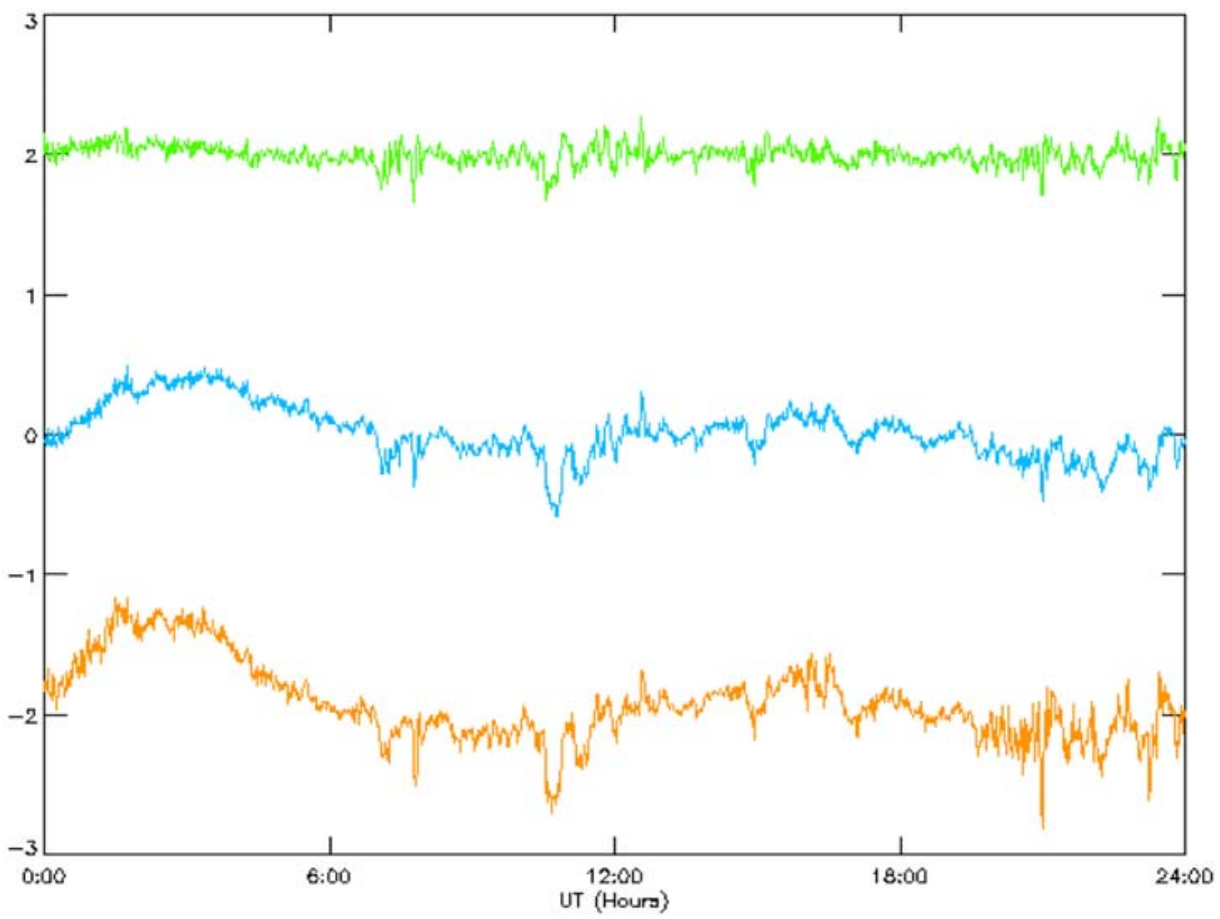

Figure 7. Plots of (a) Charters Towers magnetometer $\mathrm{H}$ - and D-component data (red and yellow, respectively) and (b) $\mathrm{dB} / \mathrm{dt}$ data (green) scaled by factor 0.2 with offset applied for presentation, GE data (blue) scaled by factor 0.2 , and PSP data (orange) in volts recorded in north QLD during a geomagnetic quiet day, 13 November 2004. 
[25] Acknowledgments. The authors would like to thank H. Borek, Alinta, G. Cope, M. Davidson, and other members of the Australian Pipeline Industry Association for assistance in acquiring the 2006 PSP data set and useful discussions. We would also like to thank R. Hoogsteyns, Enertrade, Brisbane, QLD, for providing the PSP data from the north QLD pipeline segment. The Charters Towers magnetometer data used in this analysis were supplied courtesy of Geoscience Australia.

\section{References}

Australian members of Joint Standards Australia/Standards New Zealand Committee MT-014 (2004), Cathodic protection of metals. Part 1: Pipes and cables, Aust. Stand. 2832.1, Stand. Aust. Int., Sydney, NSW, Australia.

Beamish, D., T. D. G. Clark, E. Clarke, and A. W. P. Thomson (2002), Geomagnetically induced currents in the UK: Geomagnetic variations and surface electric fields, J. Atmos. Sol. Terr. Phys., 64, 17791792, doi:10.1016/S1364-6826(02)00127-X.

Boteler, D. H. (2000), Geomagnetic effects on the pipe-to-soil potentials of a continental pipeline, Adv. Space Res., 26, 15-20, doi:10.1016/S0273-1177(99)01020-0.

Boteler, D. H., and W. H. Seager (1998), Telluric currents: A meeting of theory and observation, Corrosion, 54(9), 751-759, doi:10.5006/ 1.3284894 .

Boteler, D. H., R. J. Pirjola, and H. Nevanlinna (1998), The effects of geomagnetic disturbances on electrical systems at the Earth's surface, Adv. Space Res., 22, 17-27.

Cagniard, L. (1953), Basic theory of the magneto-telluric method of geophysical prospecting, Geophysics, 18(3), 605-635, doi:10.1190/ 1.1437915.

Caldwell, T. G., H. M. Bibby, and C. Brown (2004), The magnetotelluric phase tensor, Geophys. J. Int., 158, 457-469, doi:10.1111/j.1365246X.2004.02281.x.

Campbell, W. H. (1978), Induction of auroral zone electric currents within the Alaskan pipeline, Pure Appl. Geophys., 116, 1143-1173, doi:10.1007/BF00874677.

Campbell, W. H. (1986), An interpretation of induced electric currents in long pipelines caused by natural geomagnetic sources and the upper atmosphere, Surv. Geophys., 8, 239-259, doi:10.1007/ BF01904061.

Campbell, W. H. (1989), An introduction to quiet daily geomagnetic fields, Pure Appl. Geophys., 131, 315-331, doi:10.1007/BF00876831.

Campbell, W. H., C. E. Barton, F. H. Chamalaun, and W. Welsh (1998), Quiet-day ionospheric currents and their application to upper mantle conductivity in Australia, Earth Planets Space, 50, 347-360.

Favetto, A., and A. Osella (1999), Numerical simulation of currents induced by geomagnetic storms on buried pipelines: An application to the Tierra Del Fuego, Argentina, gas transmission route, IEEE Trans. Geosci. Remote Sens., 37(1), 614-619.

Fernberg, P. A., C. Samson, D. H. Boteler, L. Trichtchenko, and P. Larocca (2007), Earth conductivity structures and their effects on geomagnetic induction in pipelines, Ann. Geophys., 25, 207-218.

Gummow, R. A., and P. Eng (2002), GIC effects on pipeline corrosion and corrosion control systems, J. Atmos. Sol. Terr. Phys., 64, 17551764, doi:10.1016/S1364-6826(02)00125-6.

Hejda, P., and J. Bochnicek (2005), Geomagnetically induced pipe-tosoil voltages in the Czech oil pipelines during October-November 2003, Ann. Geophys., 23, 3089-3093.

Kappenman, J. (2001), Advanced geomagnetic storm forecasting for the electric power industry, in Space Weather, Geophys. Monogr. Ser., vol. 125, edited by P. Song, H. J. Singer, and G. L. Siscoe, pp. 353358, AGU, Washington, D. C.

Lilley, F. E. M., L. J. Wang, F. H. Chamalaun, and I. J. Ferguson (2001), The Carpentaria electrical conductivity anomaly, Queensland, as a major structure in the Australian plate, GSAA Monogr., 201, 1-16.

Martin, B. A. (1993), Telluric effects on a buried pipeline, Corrosion, 49(4), 343-350, doi:10.5006/1.3316059.

Olsen, N., and A. Kuvshinov (2004), Modeling the ocean effect of geomagnetic storms, Earth Planets Space, 56, 525-530.

Osella, A., and A. Favetto (2000), Effects of soil resistivity on currents induced on pipelines, J. Appl. Geophys., 44, 303-312, doi:10.1016/ S0926-9851(00)00008-2.
Osella, A., A. Favetto, and E. López (1998), Currents induced by geomagnetic storms on buried pipelines as a cause of corrosion, J. Appl. Geophys., 38, 219-233.

Osella, A., P. Martinelli, A. Favetto, and E. López (2002), Induction effects of 2-D structures on buried pipelines, IEEE Trans. Geosci. Remote Sens., 40(1), 197-205, doi:10.1109/36.981361.

Pirjola, R. (1982), Electromagnetic induction in the Earth by a plane wave or by fields or line currents harmonic in time and space, Geophysica, 18, 1-161.

Pirjola, R. (2002), Review on the calculation of surface electric and magnetic fields and of geomagnetically induced currents in ground-based technological systems, Surv. Geophys., 23, 71-90, doi:10.1023/A:1014816009303.

Pirjola, R. (2005), Effects of space weather on high-latitude ground systems, Adv. Space Res., 36, 2231-2240, doi:10.1016/j.asr.2003.04.074.

Pirjola, R., and A. Viljanen (1998), Complex image method for calculating electric and magnetic fields produced by an auroral electrojet of finite length, Ann. Geophys., 16, 1434-1444, doi:10.1007/s00585998-1434-6.

Pulkkinen, A., A. Viljanen, K. Pajunpaa, and R. Pirjola (2001a), Recordings and occurrence of geomagnetically induced currents in the Finnish natural gas pipeline network, J. Appl. Geophys., 48 , 219-231, doi:10.1016/S0926-9851(01)00108-2.

Pulkkinen, A., R. Pirjola, D. Boteler, A. Viljanen, and I. Yegorov (2001b), Modelling of space weather effects on pipelines, J. Appl. Geophys., 48, 233-256, doi:10.1016/S0926-9851(01)00109-4.

Pulkkinen, A., R. Pirjola, and A. Viljanen (2008), Statistics of extreme geomagnetically induced current events, Space Weather, 6, S07001, doi:10.1029/2008SW000388.

Stening, R., T. Reztsova, and L. H. Minh (2005), Day-to-day changes in the latitudes of the foci of the $S q$ current system and their relation to equatorial electrojet strength, J. Geophys. Res., 110, A10308, doi:10.1029/2005JA011219.

Trichtchenko, L., and D. H. Boteler (2002), Modelling of geomagnetic induction in pipelines, Ann. Geophys., 20, 1063-1072.

Trichtchenko, L., and D. H. Boteler (2004), Modeling geomagnetically induced currents using geomagnetic indices and data, IEEE Trans. Plasma Sci., 32(4), 1459-1467, doi:10.1109/TPS.2004.830993.

Viljanen, A. (1997), The relation between geomagnetic variations and their time derivatives and implications for estimation of induction risks, Geophys. Res. Lett., 24(6), 631-634, doi:10.1029/97GL00538.

Viljanen, A., and R. Pirjola (1989), Statistics on geomagneticallyinduced currents in the Finnish $400 \mathrm{kV}$ power system based on recordings of geomagnetic variations, J. Geomagn. Geoelectr., 41(4), 411-420.

Viljanen, A., and R. Pirjola (1994a), Geomagnetically induced currents in the Finnish high-voltage power system, Surv. Geophys., 15, 383409, doi:10.1007/BF00665999.

Viljanen, A., and R. Pirjola (1994b), On the possibility of performing studies on the geoelectric field and ionospheric currents using induction in power systems, J. Atmos. Terr. Phys., 56, 1483-1491, doi:10.1016/0021-9169(94)90115-5.

Viljanen, A., O. Amm, and R. Pirjola (1999), Modeling geomagnetically induced currents during different ionospheric situations, J. Geophys. Res., 104(A12), 28,059-28,071, doi:10.1029/1999JA900337.

Waters, C. L., F. W. Menk, and B. J. Fraser (1991), The resonance structure of low latitude Pc3 geomagnetic pulsations, Geophys. Res. Lett., 18(12), 2293-2296, doi:10.1029/91GL02550.

Waters, C. L., F. W. Menk, and B. J. Fraser (1994), Low latitude geomagnetic field line resonance: Experiment and modeling, J. Geophys. Res., 99(A9), 17,547-17,558, doi:10.1029/94JA00252.

Waters, C. L., R. A. Marshall, and R. Hoogsteyns (2006), Telluric currents induced in a North Queensland gas pipeline by geomagnetic variations, paper presented at WARS2006, Natl. Comm. for Radio Sci., Leura, N. S. W., Australia, 15-17 Feb.

R. A. Marshall, IPS Radio and Space Services, Bureau of Meteorology, Level 6, 477 Pitt St., Sydney, NSW 2000, Australia. (r.marshall@ips.gov.au)

M. D. Sciffer and C. L. Waters, Centre for Space Physics, School of Mathematical and Physical Sciences, University of Newcastle, Callaghan, NSW 2308, Australia. 
Reproduced with permission of the copyright owner. Further reproduction prohibited without permission. 